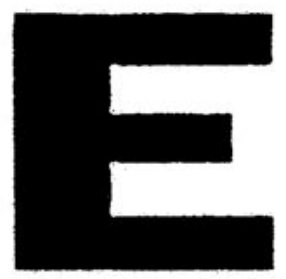

\title{
Elektronische
} Informationsverarbeitung und Kybernetik
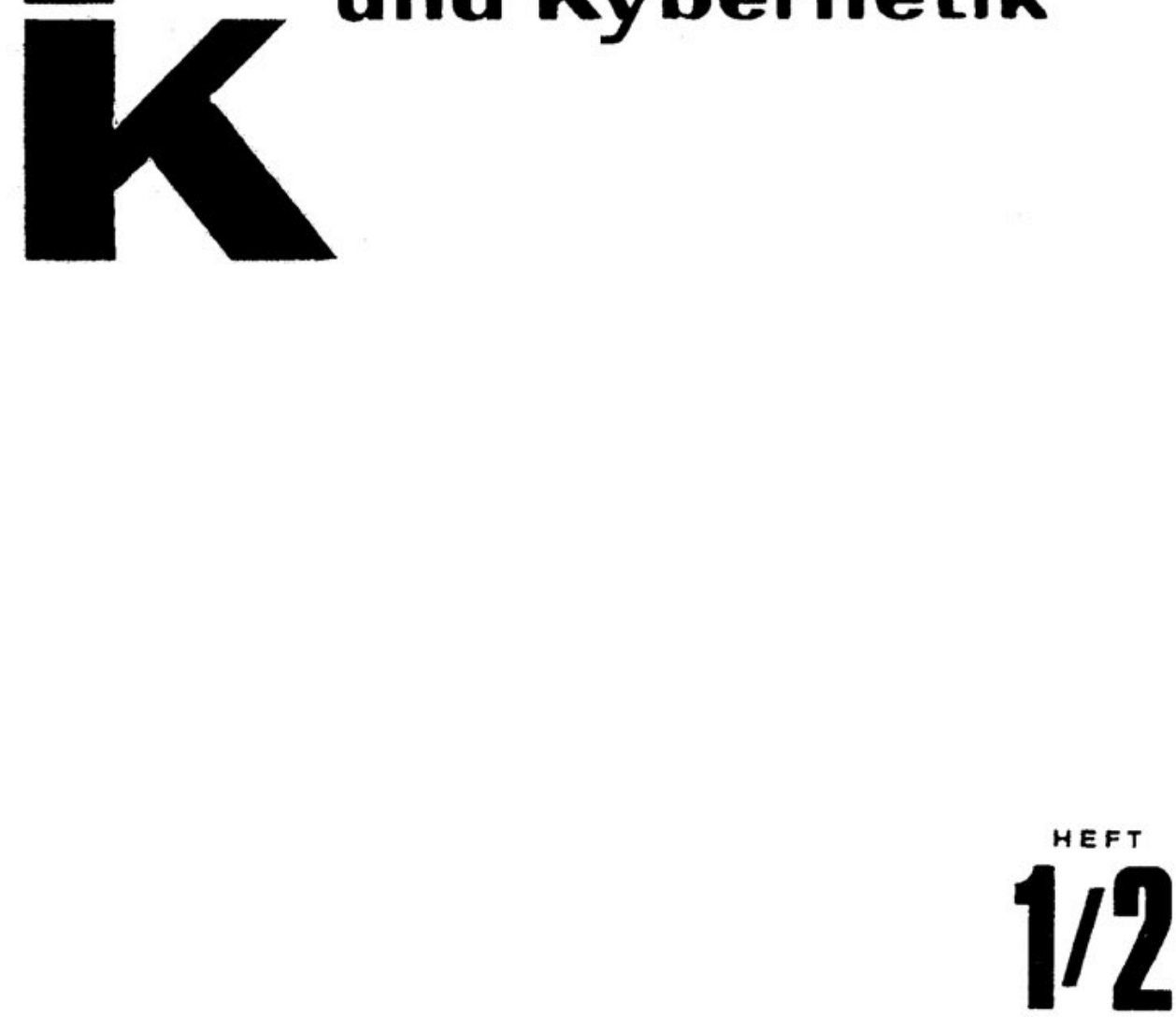

BAND 13

1977

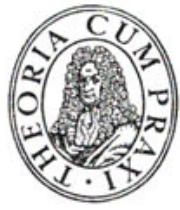




\section{REDAKTIONELLE HINIVEISE}

Munuskripte sind in zwei Exemplaren zu richten an:

Prof. Dr. H. Thiele

Soktion Mathematik der Humboldt-Univorsităt zu Berlin

DDR-1086 Berlin, Postfach 1297

oder

Prof. Dr. W. Kāmmerer

DDR-69 Jena, Sonnenbergstr. 6

oder

Dr. H. D. Modrow

Redaktion „EIK“ im Zentralinstitut für Kybernotik und Informationsprozesso

DDR-1199 Berlin-Adlershof, Rudower Chaussee 5

Manuskripte werden in deutscher, onglischer, franzosischer und russischer Sprache angenommen.

Die Autoren werden gebeten:

Manuskripte einseitig in Maschinenschrift mit mindestens zweizeiligem Abstand einzureichen (die Zahl der Abbildungen sollt möglichst klein sein).

Namen und Vornamen des Verfassers, seine Anschrift und gegebenenfalls die Institution, in der er tätig ist, sowie deren Leiter anzugeben.

Eine kurze Zusammenfassung der Arbeit von höchstens 10 Zeilen, wenn mōglich auch in zwei weiteren der obengenannten Sprachen, beizufügen.

Abbildungen auf besonderen Blättern (Transparontpapier) beizufügen.

Abbildungsunterschriften auf einem gemonderten Blatt beizufügen und, falls bezüglich der Abbildungsgrößen besondere Wünsche bestehen, diese auf den Abbildungen zu vermerken.

In einem Exemplar hervorzuhebende Textstellen schwarz zu unterstreichen, und zwar halbfetter Satz mit einer geraden Linie; kursiv (Schrägschrift) mit einer Wellenlinie; Sperrungen gestrichelt. Besondere Buchstaben durch farbige Unterstreichung zu kennzeichnen; und zwar Fraktur (I, B, ...) grün; Griechisch rot; Grotesk (A, B, ...) violett; Schreibschrift $(\mathcal{U}, \mathscr{B}, \ldots)$ braun.

Die Autoren erhalten von der Arbeit zwei Korrekturabzŭge übersandt. Sie erhalten von ihren Beitrăgen 75 Sonderdrucke kostenlos, darüber hinaus bis zu 250 Sonderdrucke gegen Berechnung. Der Verlag behălt sich für alle Beitrăge das Recht der Vervielfältigung, Verbreitung und Übersetzung innerbalb der gesetzlichen Schutzfrist vor.

Bezugsmo̊glichkeiten :

Bestellungen sind zu richten

- in der $D D R$ an eine Buchhandlung oder

an den Akademie-Verlag,

108 Berlin, Leipziger Straße 3-4

- im sozialistischen Ausland an eine Buchhandlung für fromdsprachig• Literatur oder an den zustāndigen Postzeitungsvertrieb

- in der BRD und in Westberlin an eine Buchhandlung oder an die Auslieforungestelle KUNST UND WISSEN, Erich Bieber,

Wilhelmstraße 4-6, 7 Stuttgart 1

-.. in Osterreich an den Globus-Buohvertrieb, 1201 Wien, Höchstēdtplatz 3

- im übrigen Ausland an den Internationalen Buoh- und Zoitschriftenhandel; den Buchexport, Volkseigener AuBenhandelıbetrieb der Deutschen Demokratischen Republik, DDR-701 Leipzig, Postfach 160, odor

an den Akademie-Verlag,

DDR-108 Berlin, Leipziger Straßo 3-4. 